\title{
Normal range for transdiaphragmatic pressures during sniffs with catheter mounted transducers
}

\author{
S A Evans, L Watson, A J Cowley, I D A Johnston, W J M Kinnear
}

\begin{abstract}
Background-Transdiaphragmatic pressure (sniff PDI) during maximal sniff's is a useful clinical test of inspiratory muscle function. Although a normal range has been established for sniff PDI using air filled balloons, no comparable data are available for catheter mounted pressure transducers.

Methods-Using a single catheter with two pressure transducers $15 \mathrm{~cm}$ apart, oesophageal and gastric pressures were recorded in 50 normal volunteers (25 women), five of each sex from each decade between the third and seventh decades of life. Each subject performed 10 maximal snifis at functional residual capacity.
\end{abstract}

Results-Mean (SD) sniff PDI was 149 (32) $\mathrm{cm} \mathrm{H}_{2} \mathrm{O}$ in men and 127 (22) $\mathrm{cm} \mathrm{H}_{2} \mathrm{O}$ in women. The lower limits of normal for sniff PDI (mean - 1.96 $\times$ SD) after logarithmic transformation of the data were 95 and $78 \mathrm{~cm} \mathrm{H}_{2} \mathrm{O}$ in men and women respectively.

Conclusions-With this technique transdiaphragmatic pressure can be measured using a single catheter which can easily be cleaned and reused. The values for sniff PDI are similar to those recorded previously with air filled balloons, suggesting that the method of recording pressure does not significantly affect the values obtained.

(Thorax 1993;48:750-753)

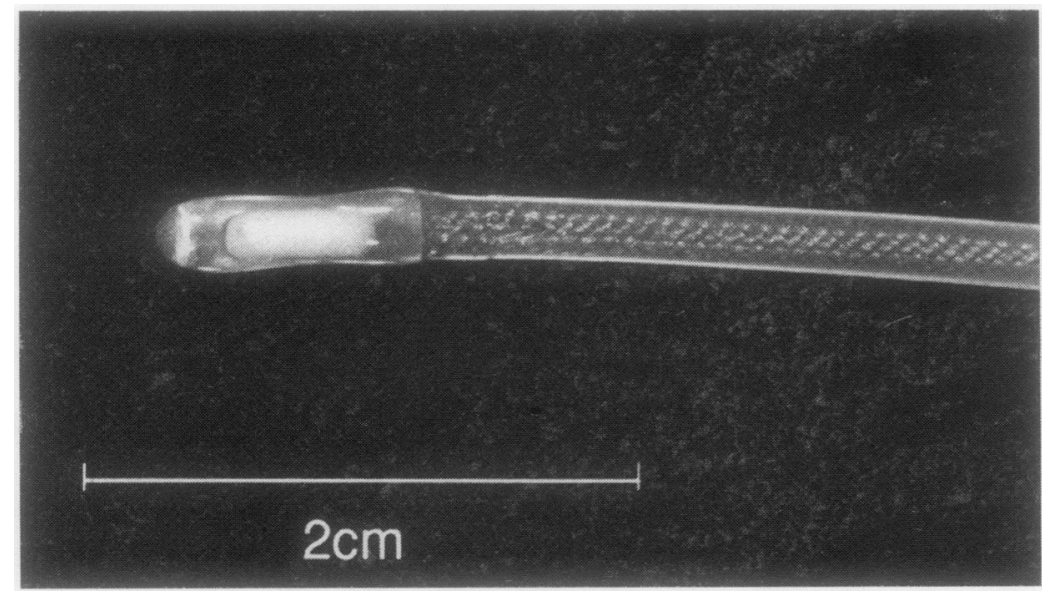

Figure 1 Catheter mounted pressure transducer
Transdiaphragmatic pressure, obtained by simultaneous measurement of oesophageal and gastric pressure during maximal sniffs, has become established as an index of $\vec{c}$ diaphragm strength. ${ }^{1}$ A normal range for sniff transdiaphragmatic pressure (sniff PDI) $\vec{x}$ recorded with air filled balloons has been $\stackrel{\oplus}{\infty}$ published, ${ }^{1}$ but it is not known whether this is applicable when other methods of recording ov gastric and oesophageal pressures are used. Catheter mounted transducers are an attractive alternative to air filled balloons because $\overrightarrow{\vec{c}}$ several transducers can be mounted on a single catheter and the pressure recorded is $\vec{\theta}$ not affected by the individual characteristics $c$ of the balloon, catheter, and connections. We have therefore established a normal range for sniff PDI with catheter mounted pressure transducers.

\section{Methods}

PRESSURE TRANSDUCERS

Two standard pressure transducers were used, mounted on a single catheter $2 \mathrm{~mm}$ in diameter (GaelTec, Dunvegan, Isle of Skye, $\vec{\partial}$ UK). This equipment is commercially available and can be sterilised by immersion in glutaraldehyde. The number, position, and pressure range of the transducers on the 8 catheter can easily be varied according to the user's requirements. Each transducer costs 은 approximately $£ 500$. We chose a distance of $D$ $15 \mathrm{~cm}$ between the two transducers, with a pressure range of $\pm 200 \mathrm{~cm} \mathrm{H}_{2} \mathrm{O}$. Figure $1 \mathrm{~N}$ shows the pressure transducer at the tip of the catheter.

The signal from the pressure transducers was passed through an isolated preamplifier (Lectromed, Letchworth, Hertfordshire, UK) and an analogue-to-digital converter (SiPlan Electronics Research, Stratford-upon-Avon, UK) to an Archimedes microcomputer 0 (Acorn Computers, Cambridge, UK).

\section{CALIBRATION}

Two different calibration techniques were used. For the first method the catheter was응 placed in a rigid chamber, the internal pressure of which could be varied above and $\frac{\bar{\partial}}{\partial}$ below atmospheric pressure with an air pump? (SiPlan Electronics Research). Using the same microcomputer as was used to record pressure to control the pump, the pressure inside the rigid chamber was changed in steps 
Figure 2 Example of sniff PDI recording obtained using catheter mounted pressure transducers. PG - gastric pressure; POES - oesophageal pressure; PDItransdiaphragmatic pressure.

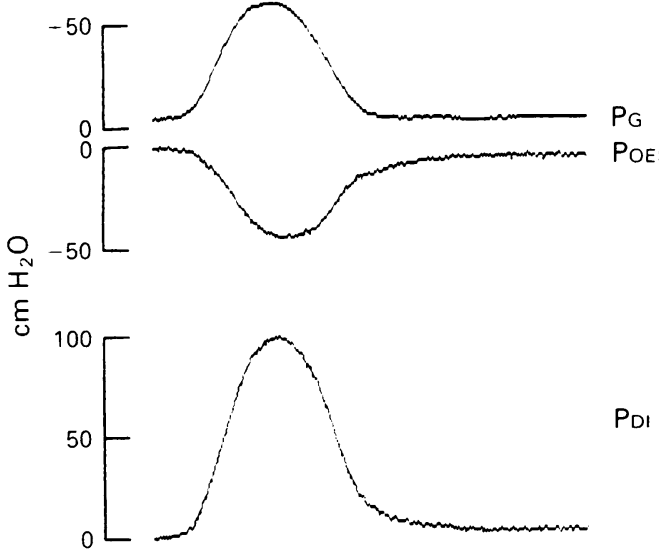

of $5 \mathrm{~cm} \mathrm{H}_{2} \mathrm{O}$ from $-60 \mathrm{~cm} \mathrm{H}_{2} \mathrm{O}$ to $+60 \mathrm{~cm}$ $\mathrm{H}_{2} \mathrm{O}$ relative to atmospheric pressure, measured with a water manometer.

For the second calibration technique we used only pressures above atmospheric, achieved by immersing the catheter into a $2 \mathrm{~cm}$ diameter hollow Perspex tube which was filled with water. The signal from the pressure transducers was recorded as the depth of immersion was increased in steps of $5 \mathrm{~cm}$. This calibration was carried out twice, once with the water at room temperature $\left(20^{\circ} \mathrm{C}\right)$ and once at body temperature $\left(37^{\circ} \mathrm{C}\right)$.

\section{NORMAL RANGE FOR SNIFF PDI}

Fifty normal subjects (25 women) were studied, all of whom had normal spirometric values. To obtain an even age distribution we studied five subjects of each sex from each decade between the third and seventh decades of life. Height and weight were measured in each subject.

To record sniff PDI the catheter was advanced until both pressure transducers showed a positive pressure deflection during sniffs and then withdrawn $10 \mathrm{~cm}$. The negative deflection seen on the proximal (oesophageal) transducer during subsequent maximal sniffs was added to the positive deflection seen on the distal (gastric) transducer to obtain sniff PDI (fig 2). For gastric pressure the baseline was taken as the resting end expiratory pressure to allow for gastric muscle tone. Ten or more sniffs were performed by each subject at functional residual capacity until five reproducible sniff $\mathrm{PD}$ values were obtained. The largest of these five sniff PDI measurements was used in subsequent analysis.
Mean (SD) oesophageal, gastric, and transdiaphragmatic pressures during maximal sniffs in normal subjects in the present study and from published data obtained with air filled balloons.
STATISTICAL METHODS

Statistical calculations were made on the Archimedes computer using the "First" statistical software package (Serious Statistical Software, South Wirral, UK), the level of statistical significance being taken as $p<$ $0 \cdot 05$. Multiple linear regression was used to explore the relationship of sniff PDI with age, height, and weight.

All studies were approved by the University Hospital ethical committee.

\section{Results}

CALIBRATION

Compared with a calibration factor of 1.0 in water at $37^{\circ} \mathrm{C}$ (this being closest to the physiological conditions in which the catheter mounted pressure transducer is used) calibration in water at $20^{\circ} \mathrm{C}$ resulted in a shift in baseline equivalent to $2.6 \mathrm{~cm} \mathrm{H}_{2} \mathrm{O}$ and a calibration factor of 0.97 . In air at $20^{\circ} \mathrm{C}$ the baseline shifted by $4.0 \mathrm{~cm} \mathrm{H}_{2} \mathrm{O}$ compared with water at the same temperature and the calibration factor was 1.02 . After one hour in water at $37^{\circ} \mathrm{C}$ the baseline pressure had drifted by $0.6 \mathrm{~cm} \mathrm{H}_{2} \mathrm{O}$.

\section{NORMAL RANGE FOR SNIFF PD}

The data for oesophageal, gastric, and transdiaphragmatic pressures during sniffs are given in the table. The mean values for women were all significantly lower than those for men. Inspection of these data showed that the distributions of sniff PDI were positively skewed, the latter mainly as a consequence of high gastric pressures. Logarithmic transformation of the data corrected this skewedness, and the lower limits of normal were taken from the transformed data as 1.96 standard deviations below the mean. The lower limits of normal for sniff PDI were $95 \mathrm{~cm} \mathrm{H} \mathrm{H}_{2} \mathrm{O}$ in men and $78 \mathrm{~cm} \mathrm{H}_{2} \mathrm{O}$ in women. There was no significant relationship between any of these pressures and age, weight, or height in either sex.

\section{REPRODUCIBILITY OF SNIFF PDI}

The single determination standard deviation ${ }^{2}$ for sniff PDI, measured in 10 subjects on two occasions at least two weeks apart, was $19 \cdot 0 \mathrm{~cm} \mathrm{H}_{2} \mathrm{O}$.

\section{Discussion}

Our normal range for sniff PDI using a catheter mounted pressure transducer is similar to that for air filled balloons. ${ }^{1}$ There are several theoretical reasons why the normal range for sniff PDI recorded with a catheter mounted pressure transducer might have differed from air filled balloons. Firstly, the frequency response of the catheter mounted pressure transducer is faster than air filled balloons $^{34}$ and, during a dynamic manoeuvre such as a sniff, it might therefore record greater swings in pressure. Secondly, the catheter mounted pressure transducer records pressure at a fixed point whereas movement of the small bubble of air in the balloon 
means that pressure is recorded from the point along its length where oesophageal pressure is most negative. ${ }^{5}$ The catheter mounted pressure transducer may therefore give smaller swings in oesophageal pressure during sniffs. Thirdly, the tip of the transducer may become immersed in gastric contents whereas the air filled balloon would float on the surface. The similarity of the normal ranges suggests that none of these factors are important during measurements of sniff PDI. The difference in the contribution of oesophageal and gastric pressures to sniff PDI between our data and those published for air filled balloons is more likely to reflect the wide intersubject differences in the pattern of respiratory muscle recruitment during inspiratory manoeuvres ${ }^{6}$ than any difference in the measurement technique. Finally, the care we took to stratify our subjects meant that their age was generally greater than in the previous study. The mean age of our population was 48 years compared with 35 years in the study by Miller et al $^{1}$ but, as discussed below, age does not seem to exert a strong influence on respiratory muscle strength. We were unable to compare the height, weight, or lung volumes of our subjects with those of the previous study.

The use of air filled balloons in respiratory physiology is well established. ${ }^{7}$ They are inexpensive but do have some disadvantages. The balloons have a limited life span and each individual balloon has different characteristics which may change with repeated cleansing. The speed with which pressure changes in the balloon are conducted up to the external pressure transducer varies with the diameter of the catheter and is affected by the connectors used. ${ }^{38}$ If gastric and oesophageal pressures are to be recorded simultaneously two balloons must be inserted, and in all but the shortest experiments it is necessary to check repeatedly the volume of air in the balloon. If mouth pressure needs to be recorded a shorter balloon must be used ${ }^{9}$ and ambulatory monitoring of oesophageal pressure is difficult.

Recording pressures using catheter mounted pressure transducers within the lumen of the oesophagus or stomach is an attractive alternative. ${ }^{10}$ These catheters are now used extensively in the study of oesophageal motility. They are easy to sterilise and can be used repeatedly. They can be manufactured to cope with any range of pressures the investigator is likely to encounter, and prolonged monitoring of pressure is possible in the ambulatory patient. ${ }^{11}$ The cost of the instrument and its associated preamplifiers is similar to that of the pressure transducers which are suitable for use with air filled balloons. Calibration can be performed at room temperature in air or water without significantly influencing the calibration factors obtained as has been described previously, ${ }^{10}$ but the baseline atmospheric pressure reading should be recorded in water at $37^{\circ} \mathrm{C}$ if accurate absolute values of pressure are required. We have confirmed that the base- line drift of the catheter mounted pressure transducer is small ${ }^{1012}$ and unlikely to be important for short studies such as the measurement of sniff PDI. Such drift has been shown not to be important in assessing the static pressure-volume characteristics of the lungs. ${ }^{4}$ The baseline can be rechecked at the end of longer experiments but air filled balloons will remain preferable if accurate knowledge of absolute pressure over a long period of time is necessary, since the transducer can be opened to atmospheric pressure at intervals during the recordings. Mouth pressure during sniffs (sniff $P M$ ) can be recorded using the same transducers.

As is the case for air filled balloons ${ }^{1}$ we did not detect any significant relationship between sniff PDI and height, weight, or age. This is surprising, given the effect of these variables on other indices of lung function. Some studies have shown that minimum oesophageal pressure ${ }^{13}$ and maximum inspiratory mouth pressure ${ }^{14-16}$ are related to age in one or both sexes, this effect being more marked over the age of 55 years ${ }^{15}$ and absent in studies confined to younger subjects. ${ }^{17}$ Since only a small proportion of our subjects were aged over 55 years it is possible that a significant effect of age on sniff PDI was missed. Maximum inspiratory pressure has been shown to be related to height in women in some studies ${ }^{14}{ }^{17}$ but not in others, ${ }^{1516}$ and this relationship has not been documented in men. Weight has only been shown to be related to mouth pressures in one study. Any effect of height and weight on inspiratory muscle strength seems likely to be small and to be unimportant in predicting sniff PDI.

1 Miller JM, Moxham J, Green M. The maximal sniff in the assessment of diaphragm function in man. Clin Sci $\mathrm{O}$ 1985;69:91-6.

2 Chinn S. Statistics in respiratory medicine. 2: Repeatability and method comparison. Thorax 1991;46:454-6.

3 Jackson AC, Vinegar A. A technique for measuring fre- $N$ quency responses to pressure, volume and flow transducers. I Appl Physiol 1979;47:462-7.

4 Panizza JA, Finucane KE. Comparison of balloon and transducer catheters for estimating lung elasticity. $\mathcal{F}$ Appl co Physiol 1992;72:231-5.

5 Trop D, Peeters R, van de Woestijne HF. Localization of recording site in the esophagus by means of cardiac artifacts. F Appl Physiol 1970;29:283-7.

6 DeTroyer A, Estenne M. Limitations of measurement of $\stackrel{\mathscr{S}}{+}$ transdiaphragmatic pressure in detecting diaphragmatic weakness. Thorax 1981;36:169-74.

7 Milic-Emili J, Mead J, Turner JM, Glauser EM. Improved technique for estimating pleural pressure from esophageal balloons. F Appl Physiol 1964;2:207-11.

8 Proulx PA, Harf A, Lorino H, Atlan G, Laurent D. ¿ Dynamic characteristics of air-filled pressure transduc- $\sigma$ ers. F Appl Physiol 1979;46:608-14.

9 Koulouris N, Mulvey DA, Laroche CM, Sawicka EH, Green M, Moxham J. The measurement of inspiratory muscle strength by sniff esophageal, nasopharyngeal and mouth pressures. Am Rev Respir Dis 1989;139:641-6.

10 Gilbert R, Peppi D, Auchincloss JH. Measurement of transdiaphragmatic pressure with a single gastricesophageal probe. $\mathcal{F}$ Appl Physiol 1979;47:628-30.

11 Vantrappen G, Servaes J, Janssens J, Peeters T. Twenty four hour esophageal $\mathrm{pH}$ and pressure recording in outpatients. In: Wienbeck M, ed. Motility of the digestive patients. In: Wienbeck M, ed. Motzing

12 Beardsmore CS, Wong Y-C, Stocks J, Silverman M. 
Assessment of the catheter tip pressure transducer for use in infant lung function tests. Med Biol Eng Comput 1982;20:657-60.

13 DeTroyer A, Yernault J-C. Inspiratory muscle force in normal subjects and patients with interstitial lung disease. Thorax 1980;35:92-100.

14 Wilson SH, Cooke NT, Edwards RHT, Spiro SG Predicted normal values for maximal respiratory pressures in caucasian adults and children. Thorax 1984;39:535-8.
15 Black LF, Hyatt RE. Maximal respiratory pressures: normal values and relationship to age and sex. Am Rev Respir Dis 1969;99:696-702.

16 Vincken W, Ghezzo H, Cosio MG. Maximal static respiratory pressures in young adults: normal values and their relationship to determinants of respiratory function. Bull Eur Physiopathol Respir 1987;23:435-9.

17 Leech JA, Ghezzo H, Stevens D, Becklake MR. Respiratory pressures and function in young adults. $\mathrm{Am}$ Rev Respir Dis 1983;128:17-23.

\section{Adventitia}

During my career I have met several individuals who provided inspiration in both professional skill and personal behaviour. This anecdote relates to one of them: $\mathrm{Dr} W$ Proctor Harvey.

When resident at Georgetown Hospital I was called to examine a young man with venous thromboembolism. He was a strapping young fellow, age 26 , and this was his first admission to Georgetown Hospital but during the previous eight years he had had multiple hospital admissions for pulmonary embolism characterised by dyspnoea, severe pleuritic chest pain, and haemoptysis, and two months before he had had an inferior vena caval ligation. Examination disclosed an extremely anxious young man, writhing in pain at intervals. His vital signs were normal. Oddly, even while complaining of severe pain he was often smiling and extremely friendly.

On admission, he had been placed on heparin and had required four hourly doses of morphine for pain control. The history was compelling, but several features were disquieting. No one had seen him have haemoptysis. His recall of the local hospitals to which he had been admitted was quite hazy (he indicated that his severe pain and the narcotics impaired his recall). His affect was odd. We had just started to use perfusion lung scanning in embolic suspects on an investigational basis. It was completely normal.

I advised the patient that we needed his records from other hospitals. A strange expression (of fear?) transiently crossed his face. He said he understood and would try to remember. I further advised him that a right heart catheterisation, pulmonary angiogram and venacavagram might be necessary and began to explain the risks. He interrupted to say, "Go ahead with whatever you need. I don't need any explanation." Finally I said we would have to cut back his narcotic use. He said, "I'm in terrible pain. Please don't make me suffer; I've suffered so much."

Later that day I discussed the case with a colleague. "Ever seen a Munchausen?" he asked. Still later Dr Harvey, the team and I made rounds on the patient. He said that he was receiving "superb" care but he felt threatened by "one of the young doctors" who wanted to reduce his narcotic dose. In the conference room afterwards I presented my views to Dr Harvey. He was briefly silent and then said: "You may be right. But you know scans are not proven. No one would allow his cava to be tied if he knew it was not needed. And he has haemoptysis. You can reduce his narcotics if you wish, but we can't let patients suffer from our suspicions. One way or another, this young man needs our help."

I decided, uncertainly, to reduce his narcotics and told the patient.

The next morning his bed was empty. "Where is he?" I asked the ward resident.

"This morning he dressed, put on a red wig and signed out. I think the night nurse solved our problem. He was really complaining about the pain and the narcotic cut. She was worried so she checked him at about 2 a.m. He was sucking on his fingers and spitting blood into his basin. There was a razor blade in his other hand. He made little cuts under his cuticles, sucked the blood and spat it out. The nurse said she had better call a doctor. He told her he was leaving, signed a release, put on a red wig and left."

I sent a letter to every area hospital describing the patient. It soon became apparent that he had been admitted to many area hospitals via the emergency room, always with dyspnoea, pleuritic pain and, of course, haemoptysis. Early narcotic use had always been heavy, and as withdrawal was attempted he would sign out, complaining of poor care. He was a true "Munchausen," agreeing even to a caval ligation.

Some months later when I met Dr Harvey he said, "I apologise for not having talked to you before about $\mathrm{Mr}$-. You were correct."

I waited for an accolade.

"We all learn chiefly from our mistakes, not our successes," he said. "But, you know, patients trust us to be their advocates. Making diagnoses is good. Helping our patient is better. This young man was asking for help and we did not help him."

This is an incident I have never forgotten. Dr Harvey, with his usual gentility, had made the key point I needed to learn: not to feel triumphant for making a snazzy diagnosis but to remember that a true physician is a patient advocate. Even on my most busy, harried days, facing the most difficult patients, these are thoughts I try not to forget. And I still wonder whether $\mathrm{Mr}$ - ever received the help he needed and I did not provide.

KENNETH MOSER 